с электрохимическим конденсатором в качестве накопителя энергии рекуперации // Перспективы развития Восточного Донбасса: материалы VI Междунар. и 64-й Всерос. науч.-практ. конф. Новочеркасск, 2015. - С. 149-153.

10. Электропитание устройств и систем телекоммуникаций: учеб. пособие для вузов / В.М. Бушуев [и др.]. - М., 2009. - 384 с.

Матвеев Андрис Илмарович, аспирант кафедры «Автоматизация и роботизация технологических проиессов имени академика И.Ф. Бородина», Российский государственный аграрный университет-
МСХА имени К.А. Тимирязева. Россия.

Андреев Сергей Андреевич, канд. техн. наук, доцент кафедры «Автоматизация и роботизация технологических процессов имени академика И.Ф. Бородина», Российский государственный аграрный университет-МСХА имени К.А. Тимирязева. Россия.

127550, г. Москва, Тимирязевская улииа, 49. Тел.: (499) 977-1455.

Ключевые слова: накопители электрической энергии; ионисторы; параметрический стабилизатор напряжения; энергетический баланс; динамическая коммутация.

\title{
DYNAMIC COMMUNICATION OF IONISTORS IN POWER SOURCES OF ELEMENTS OF TELEMETRIC SYSTEMS
}

Matveev Andris Ilmarovich, Post-graduate Student of the chair "Automatization and Robotization of Technological Processes named after Academician I.F. Borodin", Russian Agrarian University, Moscow Agricultural academy named after K.A. Timiryazev. Russia.

Andreev Sergey Andreevich, Candidate of Technical Sciences, Associate Professor of the chair "Automatization and Robotization of Technological Processes named after Academician I.F. Borodin", Russian Agrarian University, Moscow Agricultural academy named after K.A. Timiryazev. Russia.

Keywords: accumulators of electric energy; ionistors; parametric voltage regulator; energy balance; dynamic commutation.

The article describes the modes of dynamic switching of ionistors, which allow to eliminate both mentioned shortcomings. Thermal losses are eliminated by replacing the parametric stabilizer with an electronic device that supplies electrical energy in a pulsed mode. In this case, the average value of the voltage on the supplied technical means can be varied in a wide range. To use the energy remaining in the ionistor at a voltage lower than the consumer's supply voltage, it is proposed to change the interconnection schemes of ionistors in the group.

удК 677.027

\section{ИССЛЕДОВАНИЕ ПЕРВИЧНОЙ ПЕРЕРАБОТКИ ЛЬНА МАСЛИЧНОГО С ПРИМЕНЕНИЕМ ИННОВАЦИОННОГО АГРЕГАТА КВЛ-1М И ТЕХНОЛОГИЧЕСКИХ СХЕМ ДОПОЛНИТЕЛЬНОЙ ОБРАБОТКИ ВОЛОКНА}

\author{
СОБОЛЕВА Елена Валерьевна, Федеральный научный цеентр лубяных культур \\ НОВИКОВ Эдуард Валерьевич, Федеральный научный центр лубяных культур \\ БЕЗБАБЧЕНКО Александр Владиславович, Федеральный научный иентр \\ лубяных культур
}

\section{ПРОКОФЬЕВ Сергей Владимирович, Федеральный научный изентр лубяных культур ВНУков Владимир Геннадьевич, Федеральный научный цеентр лубяных культур}

Представлены результаты экспериментальных и статистических исследований первичной переработки льна масличного в полевых условиях после инновационного мобильного агрегата КВЛ-1М, различных технологических схем доочистки костроволокнистой массы в заводских условиях; определены качественные показатели полученного волокна.

Введение. Для обеспечения импортозамещения особенно важно ускоренное развитие национального сельскохозяйственного производства [3], которое невозможно без работы предприятий на селе, новых технологий и инновационного, эффективного оборудова- ния отечественного производства [4]. Такие технологии и инновационные агрегаты появились и в льноперерабатывающей отрасли, в частности, для переработки масличного льна в волокно после получения из него семян. 
Несмотря на то, что интерес к льну масличному в прошлом году существенно снизился, его посевы в Центрально-черноземной зоне, Поволжье, Западной Сибири, на Северном Кавказе обеспечивают стабильность и экономическую независимость сельхозпредприятий [6]. Одной из причин снижения интереса к масличному льну является то, что переработка в РФ остается на минимальном уровне, в том числе переработка его в волокно.

Лен масличный - это источник получения не только семян [2], но и волокна для промышленности, так как в нем содержится от 24 до $34 \%$ волокна [1].

Наиболее эффективно начинать переработку соломы и тресты масличного льна в поле, что впервые определило необходимость разработки мобильного агрегата для полевых условий марки КВЛ-1М (рис. 1), который предназначен для первичной переработки льна масличного в поле с целью получения костроволокнистой массы [1]. Однако, на сегодняшний день, отсутствуют исследовательские работы по дополнительной переработке - очистке этого волокна в стационарных условиях, а также данные о прочности [5] и других качественных характеристиках короткого волокна, полученного из масличного льна, в том числе по схеме «поле-завод».

Целью работы является исследование различных технологических схем и состава технологического оборудования для доочистки первичной костроволокнистой массы, полученной в поле после инновационного агрегата КВЛ-1М, в ликвидное льноволокно и определение его качественных характеристик в условиях цеха.

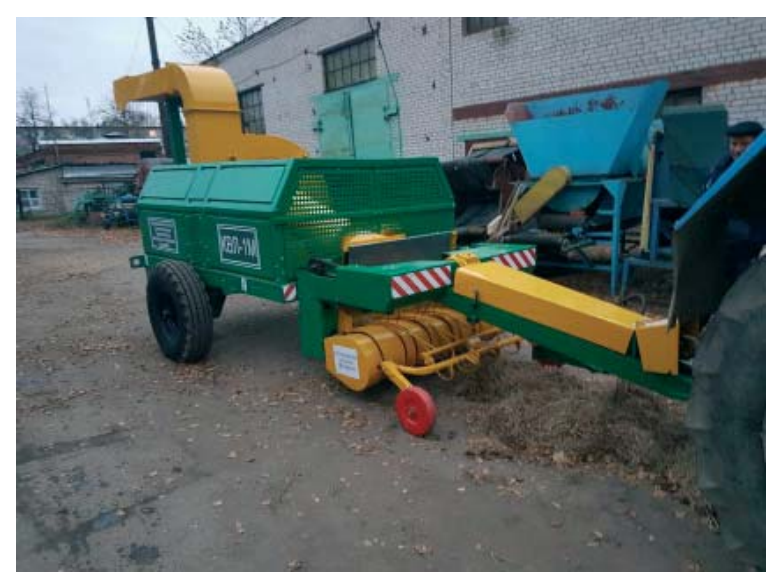

Методика исследований. Сформированные вручную из рулона валки льна масличного плотностью 0,5 и 1,0 кг/ $\mathrm{m}^{3}$ раскладывали на асфальт (см. рис. 1, а). Затем агрегат КВЛ-1М подбирал валки и перерабатывал их трепанием, в результате реализован процесс первичной переработки льна в поле. Полученную после агрегата костроволокнистая масса собирали вручную и далее дорабатывали в лаборатории на различных технологических цепочках, состоящих из серийно выпускаемого дезинтегратора и трясильных машин с верхним или нижним гребенным полем при различной линейной плотности волокна $\rho$. У полученного волокна определяли среднюю массодлину, среднюю линейную плотность, массовую долю костры и сорных примесей. Указанные показатели качества являются основными для определения производственной принадлежности волокна к производству из него той или иной готовой продукции.

В качестве сырья использовали рулон льна масличного из Владимирской области урожая 2017 г., сорт Ручеек. Валок из рулона сначала перерабатывали в КВЛ-1М. Далее доочистку полученной костроволокнистой массы проводили по следующим технологическим схемам:

1) КВЛ-1M+T+T;

2) КВЛ-1M+Д;

3) КВЛ-1M+Д+T+T;

4) КВЛ-1М+Д+Д+Т+Т, в которых КВЛ$1 \mathrm{M}$ - мобильный агрегат для получения костроволокнистой массы в полевых условиях; Д - дезинтегратор, 1990 г. выпуска; $\mathrm{T}_{(\text {в.г.) }}$ - трясильная машина с верхним гребенным полем агрегата КПМЛ-1; $\mathrm{T}_{(н . . п)}-$ ТГ-135Л - трясильная машина с нижним гребенным полем.

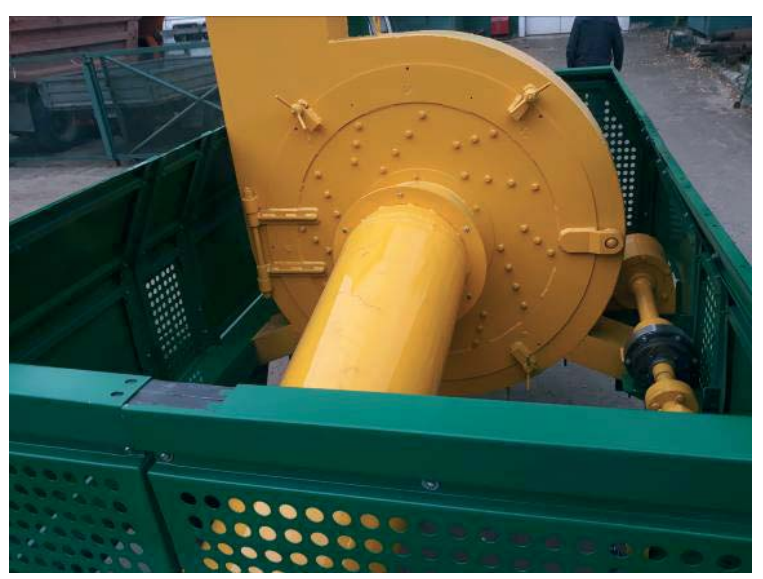

6

Рис. 1. Общий вид мобильного агрегата КВЛ-1М: а - общий вид агрегата с видом валка из масличного льна; б - вид со стороны дезинтегратора 
Результаты исследований. Результаты экспериментов представлены в табл. 1 и на рис. 2-4.

Физико-механические свойства сырья и волокна льна масличного, полученного после переработки, представленные в табл. 1, показывают:

1) после механической обработки костроволокнистой массы сырья в агрегате КВЛ$1 \mathrm{M} \mathrm{в} \mathrm{полевых} \mathrm{условиях} \mathrm{все} \mathrm{значения} \mathrm{показа-}$ телей волокна, кроме массовой доли костры, по отношению к первоначальным уменьшаются, а именно: средняя массодлина волокна при линейной плотности валка $\rho=0,5$ кг $/ \mathrm{M}^{3}$ на 23,7 мм, при $\rho=1,0$ кг $/ \mathrm{M}^{3}-$ на 36,5 мм; средняя линейная плотность волокна при $\rho=0,5$ кг/ $\mathrm{M}^{3}-$ с 9,2 до 11,3 текс, при $\rho=1,0$ кг $/ \mathrm{M}^{3}$ - с 9,2 до 10,3 текс;

2) массовая доля костры и сорных примесей остается практически неизменной: при $\rho=0,5$ кг $/ \mathrm{M}^{3}-$ с 72 до $70 \%$, при $\rho=1,0$ кг $/ \mathrm{m}^{3}$ - с 72 до $70 \%$, линейная плотность валка на массовую долю костры влияния не оказывает;

3) переработка костроволокнистой массы в стационарных условиях показала, что характеристики волокна меняются также незначительно;

4) на изменение массодлины и линейной плотности волокна не оказывают влияния ни плотность валка, ни конструкция трясильных машин в виде расположения гребенных полей (верхнее или нижнее);

5) на массовую долю костры и сорных примесей оказывают влияние линейная плотность валка с разницей $5 \%$ (при $\rho=0,5$ кг $/ \mathrm{m}^{3}-30 \%$, при $\rho=1,0$ кг $/ \mathrm{m}^{3}-$ - $40 \%$ ), она уменьшается с 70 до $30 \%$.

Аппроксимация экспериментальных данных показала, что наиболее точная зависимость характеристик волокна от технологических схем имеет степенная кривая (см. рис. 2-4), при этом величина достоверности аппроксимации $R^{2}$ при степенной зависимости выше, чем при линейной.

Для определения влияния плотности валка исходного сырья и технологических схем на основные показатели качества волокна был проведен двухфакторный дисперсионный анализ, который показал, что плотность масличного льна в валке не влияет на среднюю массодлину волокна, на его линейную плотность и массовую долю костры в нем (табл. 2).

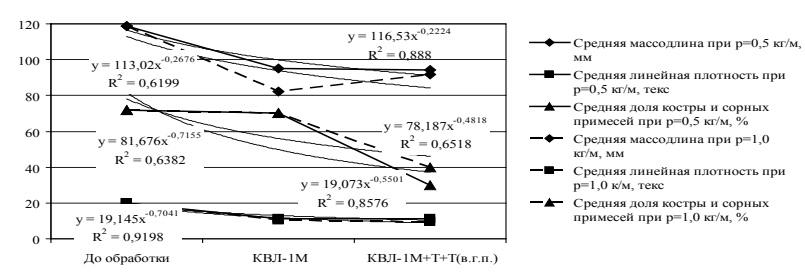

\section{Рис. 2. Изменение характеристик волокна после заводской доработки по схеме КВЛ-1М+Т (в.2.n)+T (6.2.n)}
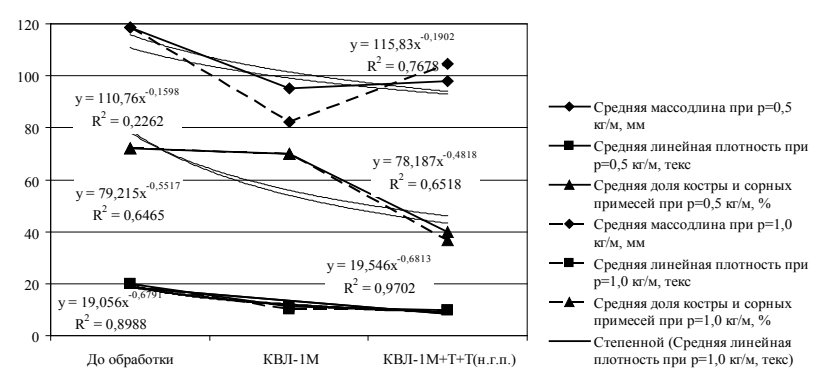

Рис. 3. Изменение характеристик волокна после заводской доработки по схеме КВЛ-1M+T (H.2.n) + T (H.2.n)

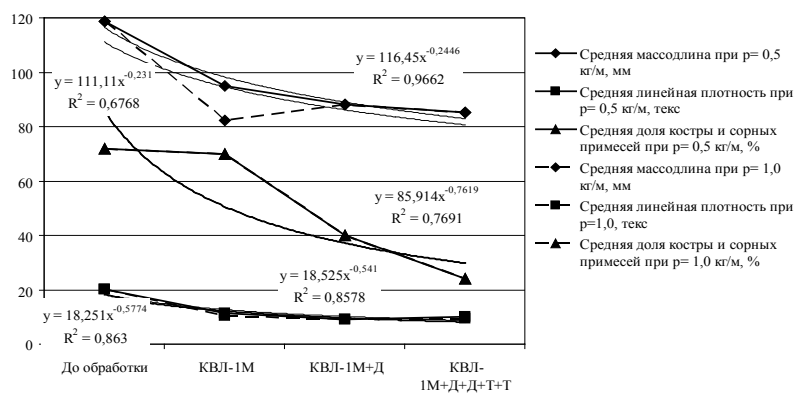

Рис. 4. Изменение характеристик волокна после заводской доработки

по схемам КВЛ-1М+Д и КВЛ-1М+Д+Д+Т +Т

Исследуемые технологические схемы оказывают влияние только лишь на массовую долю костры, т.е. 98 \% изменчивости этого показателя обусловлено влиянием схем переработки (см. табл. 2).

Заключение. По результатам проведенных экспериментальных исследований рекомендуется технология переработки масличного льна по схеме «поле-завод» со следующим составом технологического оборудования: агрегат КВЛ-1М в поле, затем два дезинтегратора и две трясильные машины с верхним или с нижним гребенным полем, т.е. КВЛ-1М+Д+Д+Т+Т. При этом готовое волокно из масличного льна может иметь следующие значения характеристик: массодлину 80-90 мм, линейную плотность 8 текс и массовую долю костры и сорных примесей 20-25 \%, может быть использовано для изготовления межвенцовых утеп- 


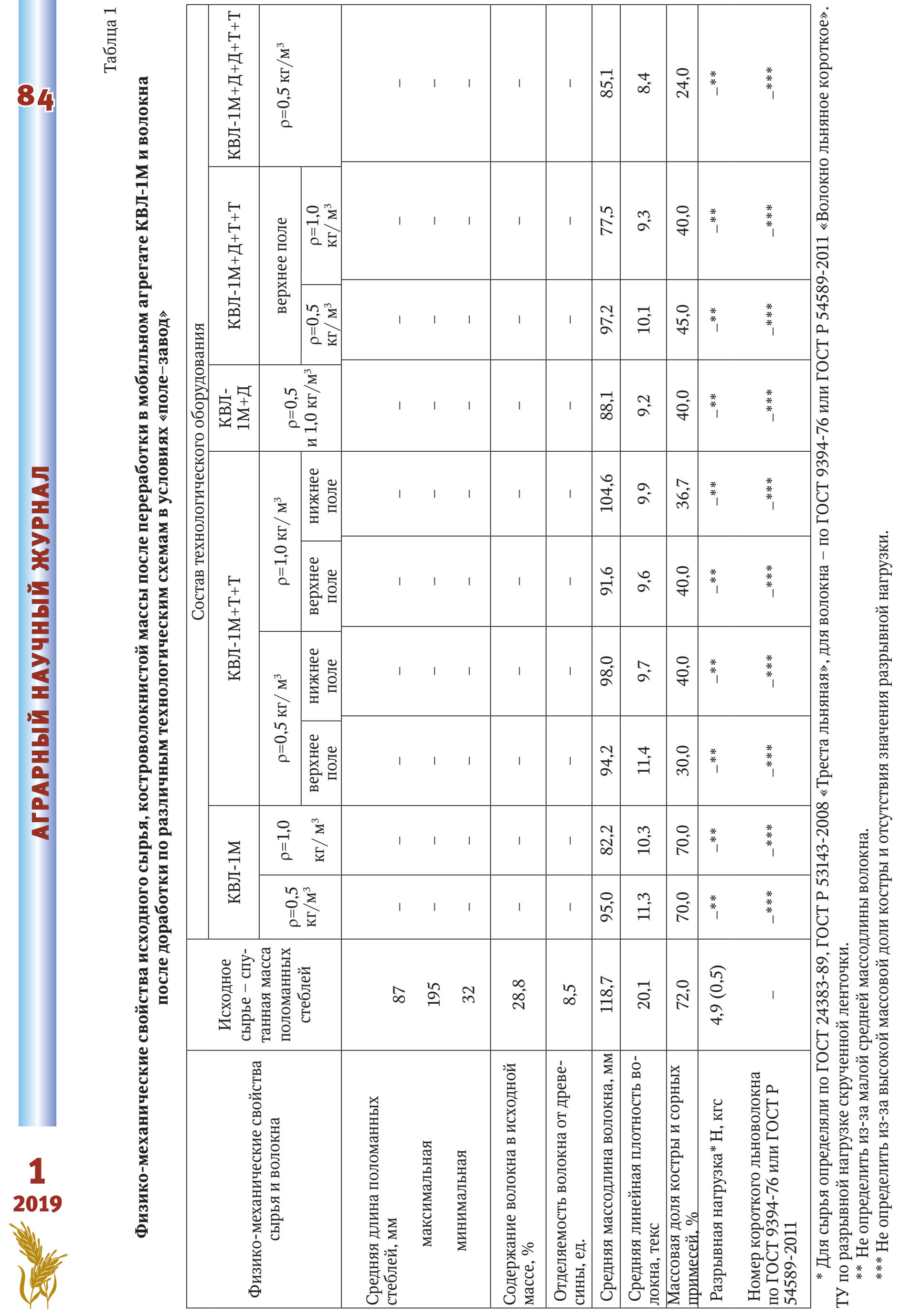


Результаты двухфакторного дисперсионного анализа

\begin{tabular}{|c|c|c|c|c|}
\hline \multirow{3}{*}{$\begin{array}{c}\text { Зависимые характеристики волокна } \\
\text { (выходной параметр) }\end{array}$} & \multicolumn{4}{|c|}{ Влияющие факторы } \\
\hline & \multicolumn{2}{|c|}{ плотность валка } & \multicolumn{2}{|c|}{ технологические схемы } \\
\hline & $\begin{array}{l}\text { влияет / } \\
\text { не влияет }\end{array}$ & $\begin{array}{c}\text { степень } \\
\text { влияния, } \\
\text { \% }\end{array}$ & $\begin{array}{l}\text { влияет / } \\
\text { не влияет }\end{array}$ & $\begin{array}{c}\text { степень } \\
\text { влияния, } \\
\text { \% }\end{array}$ \\
\hline Средняя массодлина волокна, мм & Не влияет & - & Не влияет & - \\
\hline $\begin{array}{l}\text { Средняя линейная плотность } \\
\text { волокна, текс }\end{array}$ & Не влияет & - & Не влияет & - \\
\hline Массовая доля костры и сорных примесей, \% & Не влияет & - & Влияет & 98,0 \\
\hline
\end{tabular}

лителей, санитарно-гигиенических изделий, нетканых материалов, композитов, а также в целлюлозно-бумажной, трикотажной, обувной, химической и энергетической промышленностях, медицине, автомобилестроении, строительстве и др.

\section{СПИСОК ЛИТЕРАТУРЫ}

1. Исследование характеристик масличного льна / А.В. Безбаченко [и др.] // Известия высших учебных заведений. Технология текстильной промышленности. - 2016. - № 1 (361). С. 58-61.

2. Масличный лен как глобальный сырьевой ресурс для производства волокна / Э.В. Новиков [и др.] // Молочнохозяйственный вестник. 2017. - № 3 (27). - С. 187-203.

3. Ниткин A.A. Теоретические аспекты повышения эффективности эксплуатации колесных тракторов на основе изменения тягово-сцепных характеристик шины и установки спаренных колес на почвах с низкой несущей способностью // Аграрный научный журнал. - 2018. № 4. - С. 52-54.

4. Рыбалкин Д.А., Елисеев М.С. Технико-экономическое обоснование внедрения молоткового измельчителя лузги // Аграрный научный журнал. - 2017. - № 12. - С. 76-78.
5. Соболева Е.В., Новиков Э.В. Связь показателей качества короткого волокна и льна масличного // Инновационные разработки для производства и переработки лубяных культур: материалы Междунар. науч.-практ. конф. Тверь. - 2017. - С. 326-333.

6. https://www.rosflaxhemp.ru/fakti-i-cifri/ spravochnie-materiali.html/id/2260.

Соболева Елена Валерьевна, старший научный сотрудник, Федеральный научный изентр лубяных культур. Россия.

Новиков Эдуард Валерьевич, канд. техн. наук, доцент, ведущий научный сотрудник, Федеральный научный иентр лубяных культур. Россия.

Безбабченко Александр Владиславович, cmapший научный сотрудник, Федеральный научный иентр лубяных культур. Россия.

Прокофьев Сергей Владимирович, научный сотрудник, Федеральный научный изентр лубяных культур. Россия.

Внуков Владимир Геннадьевич, канд. техн. наук, ведущий научный сотрудник, Федеральный научный центр лубяных культур. Россия.

170041, г. Тверь, Комсомольский пр., 17/56.

Тел.: (4822) 41-61-10.

Ключевые слова: лен масличный; характеристики; короткое льноволокно; агрегат КВЛ-1М; дезинтегратор; трясильная машина; слой льносырья; гребенное поле.

\section{RESEARCH OF PRIMARY PROCESSING OF OILY FLAX WITH USE OF THE KVL-1M INNOVATIVE UNIT AND TECHNOLOGICAL SCHEMES OF ADDITIONAL PROCESSING OF FIBRE}

Soboleva Elena Valeryevna, Senior Researcher, $\mathrm{Fe}$ deral Scientific Center for Fibre Crops. Russia

Novikov Eduard Valerievich, Candidate of Technical Sciences, Leading Researcher, Federal Scientific Center for Fibre Crops. Russia.

Bezbabchenko Alexander Vladislavovich, Senior Researcher, Federal Scientific Center for Fibre Crops. Russia

Prokofiev Sergey Vladimirovich, Researcher, Federal Scientific Center for Fibre Crops. Russia

Vnukov Vladimir Gennadievich, Candidate of Technical Sciences, Leading Researcher, Federal Scientific Center for Fibre Crops. Russia.
Keywords: oily flax; characteristics; short flax fibre; KVL-1M unit; disintegrator; tow shaker, layer of flax raw material; comb field.

Results of experimental and statistical studies of primary processing of oil flax in field conditions after the innovative mobile KVL-1M unit, various technological schemes of afterpurification of chaff-fiber mass in flax plant conditions and definition of quality indicators of the received fiber are presented in the article. 